\title{
Decision Support Tools for Warfighters
}

\author{
Steven C. Gordon* \\ Technical Director \\ Air Force Agency for Modeling and Simulation \\ 12350 Research Parkway \\ Orlando, Fl 32826 \\ (407) 208-5776 \\ steve.gordon@afams.af.mil
}

\begin{abstract}
As the United States Armed Forces prepare now for an uncertain future, the need for shortened and otherwise improved decision-making cycles is growing. The types of contingencies for which military forces may be tasked and the kinds of opposition forces that the Services may face in Joint and Coalition operations are changing. Certainly, pressure to shorten reaction times, tailor a light and lean reaction force, and end the contingency favorably and quickly will grow. Our Armed Forces can no longer prepare for primarily one enemy and a handful of potential conflict scenarios.

Numerous data-gathering systems can help our forces maintain information superiority in combat. Yet, there is a downside here too. Information superiority can not necessarily guarantee knowledge of the right information or assure correct decisions will be made. Information must be sorted, prioritized, analyzed, and presented using improved combat efficiency as the primary focus. Operational commanders need the right decision support tools to help them maintain information dominance, situational awareness, and an accelerated decision cycle.
\end{abstract}

\section{Introduction}

In future military operations, the United States military will face sophisticated opposition forces that can at least delay or confound friendly coalition actions. Maintaining an information advantage and building a knowledge advantage over enemy forces will require new automated decision support tools, including some predictive modeling and simulation (M\&S) systems.

Technology improvements have made development of automated decision support tools feasible. Advanced visualization, automated data retrieval, simulation of future operations, and prediction of enemy actions can be used to more effectively plan and execute modern military operations. In 1998, the Warrior Preparation Center in Germany conducted NIMBLE LION using air power simulations normally used for training to improve the Air Tasking Order (ATO) build process. NIMBLE LION was successful and was improved upon to assist planning and execution of the Air War Over Serbia (AWOS) in Operation ALLIED FORCE. Analysis support to ALLIED

\footnotetext{
* Decision Support Tools for Warfighters is a research area to consolidate requirements and anticipate M\&S needs for predictive decision support. As such, this paper does not represent official Air Force positions on decision support requirements nor potential solutions.
} 
FORCE Senior Commanders was a key innovation [Kenkel, 1999]. From both NIMBLE LION and AWOS, lessons learned point to the need for improved decision support tools. For instance, the initial NIMBLE LION after action review included findings that visualization tools initially were not adequate and ATO analysis tools were not robust [WPC, 1998].

Lessons learned like these, with advanced technology available as an engine for change, have reinforced the need for improved decision support tools for warfighters. The clear danger in not fielding adequate decision support tools for operations perhaps waiting for that "ideal" new tool in development -- can be a lengthy or flawed planning process and slow reaction to enemy provocation. Future enemies may not allow several months for coalition force beddown as in DESERT STORM nor provide the opportunity to endure poor tanker orbit locations for many days into the operation as in AWOS [Begert, 1999]. The success of using training simulations for decision support in NIMBLE LION and a dedicated analysis section in ALLIED FORCE points toward some key next steps in improving decision support to the warfighter.

Establishing clear requirements for decision support tools for warfighters and testing and experimenting with candidate solutions are the next logical steps. The paper will begin this definition process with a discussion of how command and control (C2) is structured in a typical contingency and a hypothetical storyboard of a developing, potential contingency operation. The main actors in the contingency response, the issues they face, and the types of automated decision tools that could accelerate and improve contingency response will be summarized in order to explain how these tools might be used.

Then, two ways of describing the requirements will be discussed. First, decision support tool requirements will be described in terms of the six steps used for crisis action planning (CAP): situation development, crisis development, course of action (COA) development, COA selection, execution planning, and execution. Tools that can improve the effectiveness of CAP can be discussed in detail for each stage. Alternatively, the decision support tool requirements will be listed and referenced to the Air Force Tasks and Subtasks relating to Command and Control from Air Force Doctrine Document 1-1. Decision support tool requirements can be generalized as capability needs for efficient population and update of databases, automated tools for logistics decision making, COA analysis, ATO options and quality control, and visualization of analysis. Subtasks can be further refined into detailed requirements for decision support tools.

\section{Requirements for Decision Support Tools}

Regional Commander in Chief (CINC), Air Force Major Command, and Numbered Air Force (NAF) staffs monitor situations within their areas of responsibility. When a potential crisis begins to develop -- whether in response to a natural disaster, combat, or mixture of these responsible headquarters build knowledge of the situation and area, and they evaluate options. The responsible CINC may designate a Joint Force Commander (JFC), who in turn may designate component commanders, such as the Air Force Forces (AFFOR) Commander or the Joint Force Air Component Commander (JFACC), as appropriate. The AFFOR or the JFACC (most likely a NAF Commander or NAF/CC) may use an Air Operations Center (AOC) as their command post to plan, build, and execute aerospace operations in support of the crisis resolution. Products 
commonly associated with an AOC are the daily airspace control order (ACO) to partition airspace and the air tasking order (ATO) to allocate resources and designate targets. The JFACC staff and the AOC balance competing demands to produce advice to the JFC, planning documents, and daily ACOs and ATOs; one view of this balancing act is in Figure 1.

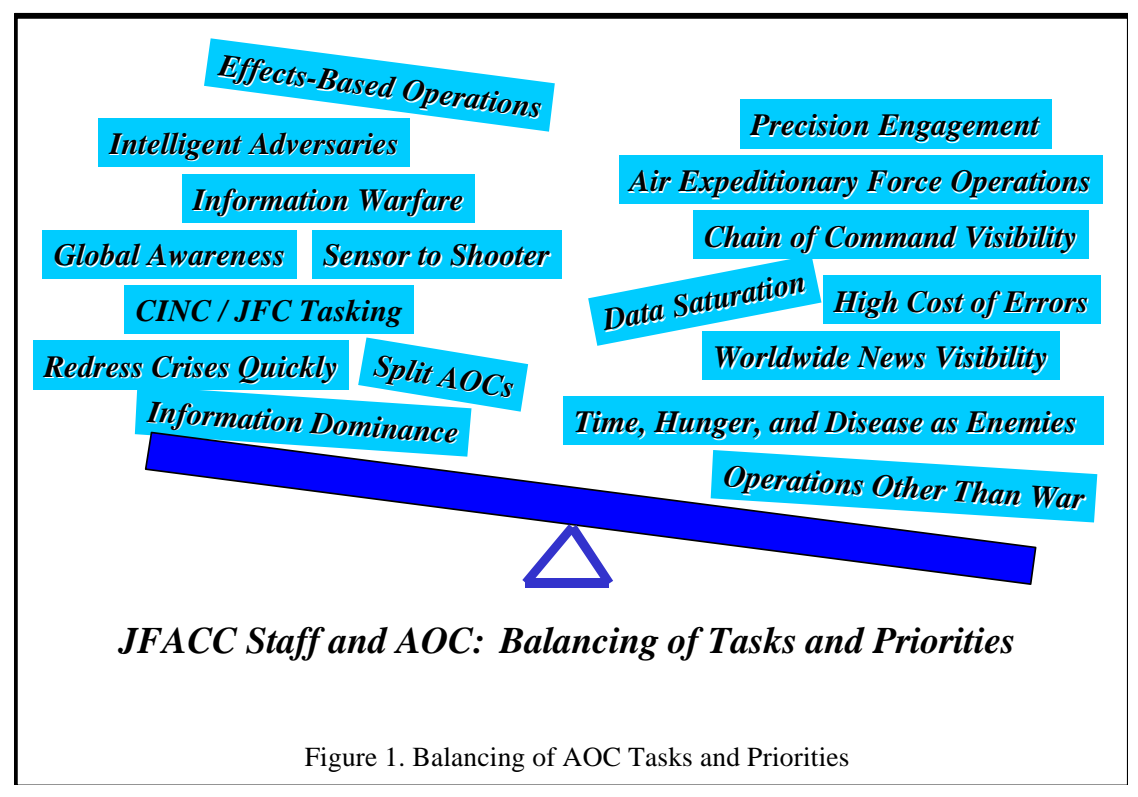

Components will participate as part of the designated Joint or Coalition team, and specific "deliverables" are expected from these components, which conduct military operations in order to satisfy higher headquarters (HHQ) objectives. A depiction of general types of AFFOR/JFACC "deliverables" is in Figure 2.

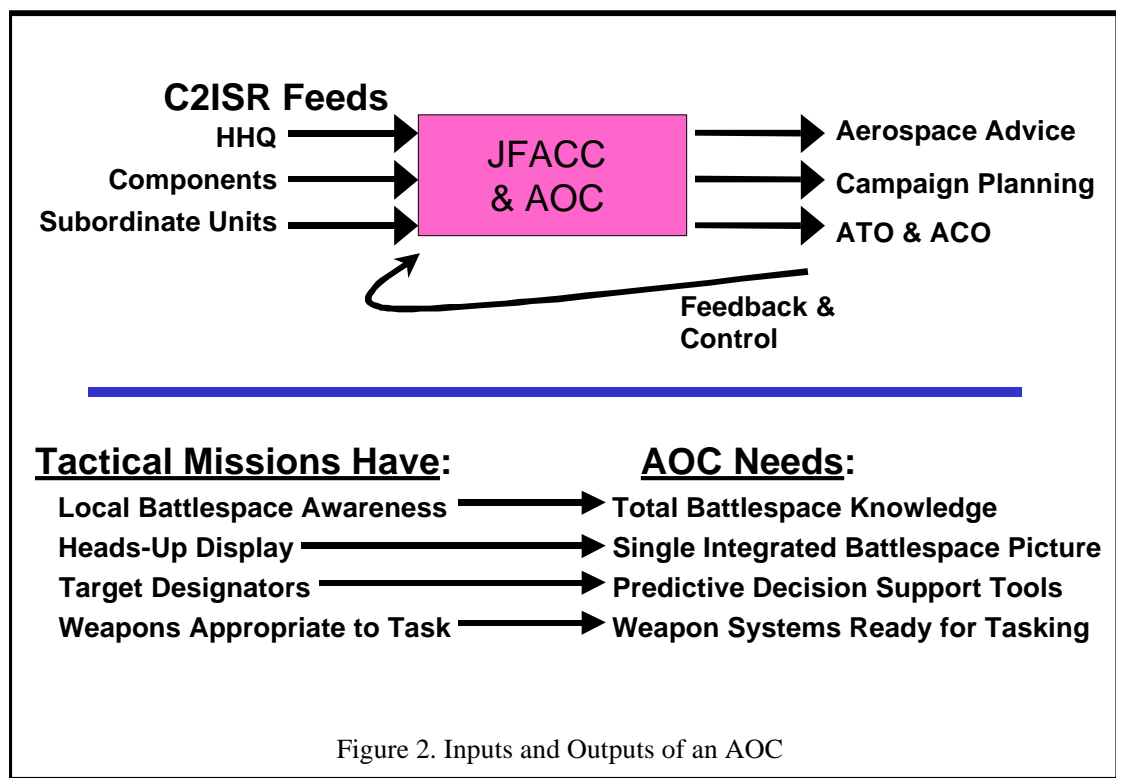


Key to future warfighting is how the AFFOR or JFACC formulates the aerospace advice, conducts campaign planning, and produces ACOs and ATOs that are faithful to CINC/JFC objectives and as accurate as possible. Decision support tools can be used to build component knowledge, evaluate options, and support task force operations. They can provide the predictive feedback and control to assist commanders in each of these areas. With the right tools, the AOC can build battlespace knowledge with integrated visualization and predictive tools to manage uncertainty. Other automated tools can help decision-makers change taskings and redirect assets. Air Force Chief of Staff, General Michael Ryan, stated use of all available information sources "...to find where the important leverage points are in the battlespace...are the kinds of things we will have to work even harder in the future because that is where we are going to get improved capability of the force." 1 Decision support tools, especially predictive tools, will assist commanders in finding the key leverage points on both sides of the conflict.

While contingency response may simplistically be viewed as a planning task followed distinctly by a series of execution phases, in reality, contingency response requires continuous planning and analysis of execution. The previous COA or commanders' objectives may change, or daily priorities may shift; and missions can be redirected in minutes. Campaign objectives, plans, and daily execution are examined in light of changing battlespace circumstances. This interrelationship of planning and execution is depicted in Figure 3.

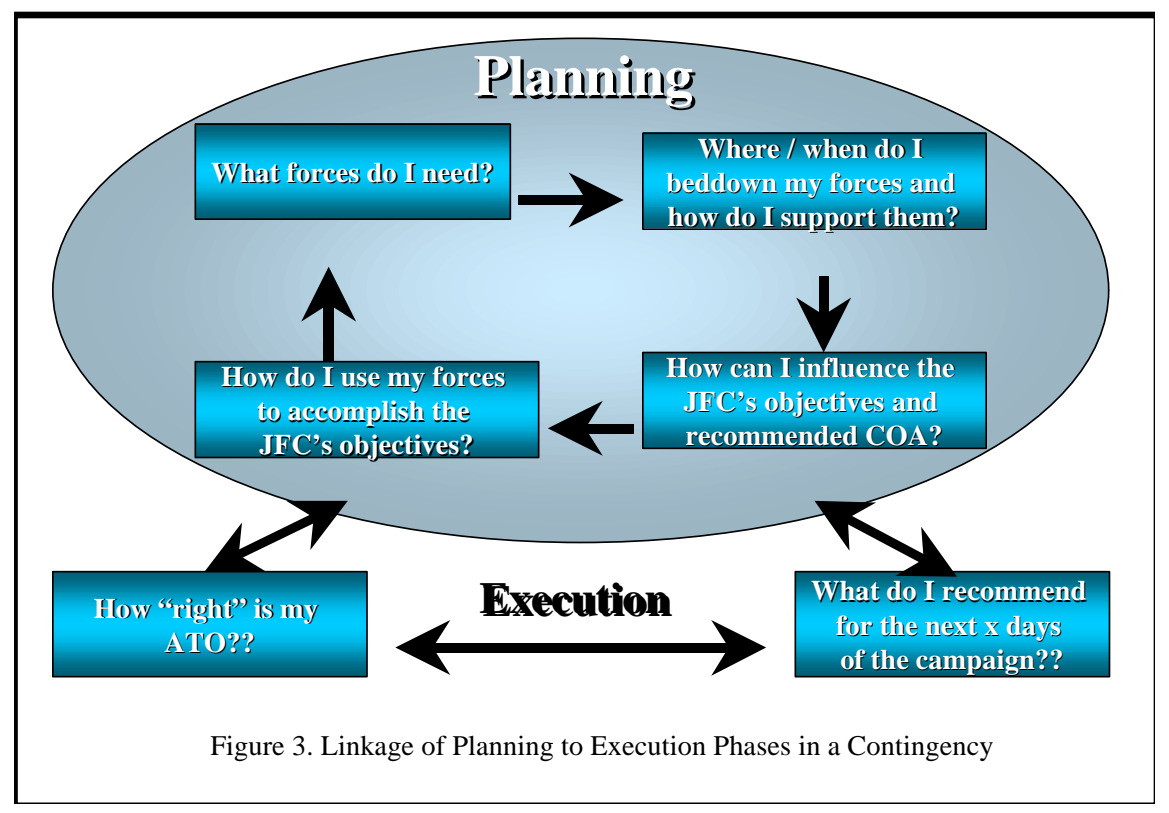

Military operations are seldom against a "stationary enemy", and future opponents will undoubtedly pursue asymmetric attacks against United States or Coalition military weak points (vice symmetric strength against strength, attrition attacks). Our forces' power and success in

\footnotetext{
${ }^{1}$ General Michael Ryan, Air Force Chef of Staff, Air Force News 00-01, January 2000
} 
conflicts may well be based on the ability to anticipate enemy actions, mask coalition weak points, defend against asymmetric attacks, and make decisions faster than opposition forces.

\subsection{Storyboard of Decision Support Tool Uses in Contingency Response}

Currently, AOCs have automated tools that help generate ACOs and ATOs and projection systems for graphics portrayal. Beyond that, map boards, Post-It notes, and "sand" tables are used for situational awareness. Other tools can improve contingency response. The storyboard at Figure 4 is designed to illustrate the types of tools that are required for one selected contingency story.

\begin{tabular}{|c|c|}
\hline $\begin{array}{l}\text { 1. Situation: Potential Humanitarian } \\
\text { Assistance, with Organized Rebel } \\
\text { Interference Expected } \\
\text { Location: Wherever You Neglected to } \\
\text { Gather Infrastructure Data }\end{array}$ & $\begin{array}{l}\text { 2. Timeline: } \\
\text { - CINC Designates JFC } \\
\text { - JFC and AFFOR Geo Separated } \\
\text { - NAF/CC Designated AFFOR } \\
\text { - No Decision on Need for JFACC } \\
\text { - JTF Staff Accelerating CAP } \\
\text { - AFFOR Assists in Drafting } 2 \text { or } 3 \\
\text { COAs and Offers Advice to JFC } \\
\text { - AFFOR: Quantify Goodness of COAs }\end{array}$ \\
\hline $\begin{array}{l}\text { 3. Issue: } \\
\text { - Geographic Separation Complicates CAP } \\
\text { Coordination } \\
\text { - AFFOR Awaits JFACC Designation } \\
\text { - May Deploy: AOC Locations and } \\
\text { Timing Selected } \\
\text { - Must Assist in CAP } \\
\text { - Must Generate Aerospace Plan } \\
\text { - Must Begin Work on First ACOs and } \\
\text { ATOs } \\
\text { - Deploy Initial Munitions Kit }\end{array}$ & $\begin{array}{l}\text { 4. Tool Needs: } \\
\text { - Force Beddown Assessment Tool } \\
\text { - COA Planner } \\
\text { - JFACC Logistics Planner } \\
\text { - Visualization of attack plans and ATOs } \\
\text { - Auto Router for attack plans and ATOs } \\
\text { - ATO Evaluation for COA Attainment } \\
\text { \& Survivability } \\
\text { - Advanced Visualization } \\
\text { - Responsive Analysis Shop (Reachback?) } \\
\text { - Intelligence Predictive Tools }\end{array}$ \\
\hline
\end{tabular}

\subsection{Decision Support Tool Requirements Linked to Crisis Action Planning Phases}

Decision support tools will be used to accelerate contingency response, influence Joint Force planning, and improve execution, allowing future commanders to preempt, prevent, and overwhelm adversaries. The Advanced Battlespace Information System Task Force has described the types of decision support tools needed for contingency response:

"Automated capabilities are needed to not only understand critical nodes in the adversaries' warplan and how these nodes change, but also ensure that the targets process is identifying the best targets..."2

\footnotetext{
${ }^{2}$ Advanced Battlespace Information System Task Force Report, 1996
} 
One way to describe decision support tool needs is by looking at the phases of Crisis Action Planning and relating necessary decisions (and relevant tool capabilities) to those six phases:

I. Situation development:

- Evaluate possible scenarios

- Update linked C2, information, and simulation databases

- Look at COA, force, and beddown options

- Plan initial munitions supply and logistics resupply options

- Visualize and simulate alternative air attack plans

II. Crisis development

- Use automatic feeds to update databases

- Evaluate force structure and beddown scenarios

- Plan forces at "right" levels and locations to achieve assumed objectives

- Use visualization to review enemy and potential friendly force laydowns

- Use logistics tools to predict beddown and sustainment options

- Predict enemy actions

- Test "what-if" situations

III. COA Development

- COA analysis completed through visualization, air art, and computation

- Recommend forces, locations, and COA to JFC

IV. COA selection

- JFACC develops Joint Air Ops Plan, assists Joint Force planning

- Logistics planning and ATO logistics supportability completed

- Initial munitions requirements staged

- Air strategy and centers of gravity analyzed in terms of history and operational environment research

- Alternative air attack plans analyzed via visualization and simulation

V. Execution Planning

- JFACC develops ATO 1, 2, 3...

- Visualize ACOs, looking for ineffective or problematic airspace use

- Screen ATOs for accuracy and to ensure they achieve JFC's desired effects

- Use predictive tools: gain spatial/temporal advantage to control/defeat enemy strategy

- Evaluate options and brainstorm enemy actions

- Use M\&S and analysis for experimental design over scenario space

VI. Execution

- Use simulation to predict enemy actions

- Analyze new ATOs, new branches, and sequels

- Change the aerospace operations plan to attain CINC / JFC objectives

Using analytic support -combat analysis and the right decision support tools can accelerate CAP and help commanders "experience the unexpected" through simulation excursions, improving combat effectiveness. Tactical flight leads who test-fly their combat mission via simulation and "see" the target area via imagery have considerable advantage over those that just map study. Similarly, JFACCs can "test fly" COAs, ATOs, and ACOs... and better leverage their forces. 


\subsection{Decision Support Tool Requirements Linked to Needs and Air Force Tasks ${ }^{3}$}

As an alternative, one can look at decision support tools for military operations by grouping similar requirements and cross-referencing these to the relevant Air Force Task (AFT). This type of grouping is illustrated below at a very general level. These requirements and the Air Force Tasks (see Appendix I) can be expanded into a much more detailed listing of needs.

- Efficient population and update of databases (AFT 7.1.1)

- Data sharing across C2, ISR, M\&S

- Automated tools for logistics decision making (AFT 7.3.2)

- Beddown of forces; aerial ports of debarkation

- Closure of forces and supplies; force support, re-supply

- Course of action analysis (AFT 7.3.3, 7.3.4 and 7.3.5)

- For pure MOOTW: logistics and ISR alternatives

- For warfighting: force structure, ISR, employment options

- $\quad$ ATO options and quality control (AFT 7.4.1)

- Test-fly ATO options; what-if analysis of variations

- Test-fly the ATO prior to release or prior to execution

- Visualization of analysis (AFT 7.1.1, 7.1.4, 7.1.5)

\subsection{Decision Support Tool Requirements Relating to Prediction}

Most of the decision support tool needs for military operations can be fielded using current commercial or military systems with modifications and process changes. Connectivity and automated data exchange between $\mathrm{C} 2$, information, and M\&S systems are technically achievable, yet not trivial. The Advanced Battlespace Information System Task Force Report states that the need for predictive decision support will increase because commanders need

“...M\&S to anticipate the likely courses of the battle...lean forward in the planning process, exploit opportunities, and shape expected actions to stay within the enemy's decision cycle...Models and simulations support the exploration of alternatives both to understand better what the situation might be today and how it may unfold in the future." 4

Yet, in order to meet this challenge and field capabilities, analytic support to military operations must be institutionalized, practiced in wargames, experiments, and exercises, and then adapted to serve operational commanders. M\&S support to assist the analysts in predicting enemy actions and coalition needs is a current shortcoming that will only be overcome by attempting to mold

\footnotetext{
${ }^{3}$ Air Force Task List for Command and Control in Air Force Doctrine Document 1-1, 12 August 98

${ }^{4}$ Advanced Battlespace Information System Task Force Report, 1996
} 
current commercial and military simulations into the needed predictive operational toolkit. Analysts serving operational commanders will improve the operational M\&S toolkit through use in wargames, experiments, exercises, and operations.

In many cases, predictive tools may be very capable in screening the ATO for errors of tasking or scheduling, yet very weak in determining if the ATO is one step in the right direction in achieving JFC objectives. Simulation may be limited in its ability to predict enemy actions, yet surprisingly capable in highlighting enemy threats that were not eliminated in the correct order for friendly force survival. In operations other that war, where the enemy can be hunger, disease, suffering, or death, simulation is especially weak in predicting outcomes. Yet, as our forces and the analytic shops that support them gain experience in using a simulation toolkit for operations, workarounds and acceptable limitations will be understood.

Numerous decision support tools are developed or fielded each year (see Appendix II), and a dedicated testbed for these tools and analysis shops for operational commanders can be used to screen and evaluate these tools. The dedicated testbed and analysis shops would eventually lead to configuration control and reduced unnecessary duplication. Improvements in decision support for contingency response will come much sooner with use than with waiting for the ideal simulation to be developed. Predictive tools will help commanders understand an array of futures, typical enemy actions, and key coalition weakness to mask or protect. M\&S for decision support can help lesson uncertainty, and General Michael Ryan has said, "Our people need to be trained to deal with uncertainty and the unpredictable."

\section{Conclusion}

The uncertain future we prepare for now may include very capable adversaries who will not pause between punches nor provide the United States or our coalition partners preparation time comparable to that of recent conflicts. Time will be an enemy in all military operations, and decision support tools that improve our decision cycles will be a weapon in our arsenal perhaps the most important new weapon. The requirements for decision support tools can be described in terms of the stages of crisis action planning, in terms of functional needs, and linked to the Air Force task list. Many of the requirements for these decision support tools can be met with modifications to current commercial or military systems. Linkages of databases, automatic realtime updates of data, and connectivity must be worked; but these improvements are technically feasible today. A designated Center of Expertise for Decision Support could provide the C2 testbed to engineer decision support tools and provide them to wargames, experiments, exercises, and operations. The most striking limitations of what the United States military and coalition partners will be able to field for decision support are in the predictive analysis and M\&S areas. Solutions to these shortcomings will be realized faster if selected M\&S tools are used by a dedicated analysis shop in wargames, experiments, exercises, and operations so that combat analysis teams linked to the operational commander can test, modify, and improve the M\&S toolkit. In the end, we will need to designate a suite of decision support tools including a toolkit of $M \& S$ predictive tools used by a faithful analysis shop. Operational commanders need the right

\footnotetext{
${ }^{5}$ General Michael Ryan, Air Force Chief of Staff, Air Force Symposium, Orlando, Florida, March 2000
} 
decision support tools to help them maintain information dominance, situational awareness, and an accelerated decision cycle to improve combat effectiveness.

\author{
"Airpower is like poker. A second-best hand is like none at all \\ -- it will cost you dough and win you nothing." \\ General George Kenney, USA
}

\title{
4. References
}

[ABIS, 1996] Advanced Battlespace Information System (ABIS) Task Force Report. Director of Defense Research and Engineering (OSD), Director for Command, Control, Communications, and Computer Systems (Joint Staff), www.ca.dtic.mil/dstp/96_docs/abis/, 1996.

[Begert, 1999] William J. Begert, Lieutenant General (USAF). "Kosovo and Theater Air Aerospace Power Journal. Winter, 1999.

[Begert, 11/1999] William J. Begert, Lieutenant General (USAF). Comments during Warrior Preparation Center Briefing and Tour. November 16, 1999.

[Bradshaw, 1998] Jeffrey Bradshaw. "Warrior Preparation Center (WPC) Joint Force Air Component Mission Rehearsal Improvement Project", document. CINC Initiative Fund Request, HQ USAFE/WPC. December 18, 1998.

[Cohen, 2000] William S. Cohen, Secretary of Defense. Report to Congress, Kosovo/Operation ALLIED FORCE After-Action Report. January 31, 2000.

[DeLiso, 1999] Sebastiano DeLiso, Major (USAF). "Improving the Warrior Preparation Center (WPC) Air Campaign Analysis Capability". Air Command and Staff College (Air University) Research Report AU/ACSC/99-040/1999-04, April, 1999.

[Diamond, 1999] Dick Diamond. "Kosovo Lessons Learned Study Group Final Report”, briefing. Raytheon Systems Company, July 27, 1999.

[Eaker, 1999] The Eaker Institute for Aerospace Concepts. "Operation Allied Force: Strategy, Execution, Implications", transcript of proceedings. Ronald Reagan International Trade Center, Washington, D.C., August 16, 1999.

[Ellis, 1999] James O. Ellis, Admiral (USN). "A View from the Top", briefing as Commander, Joint Task Force NOBLE ANVIL during Operation ALLIED FORCE, 1999.

[Hartley, 1998] Dr. Dean Hartley, conversations and exchange of lists of M\&S tools for operations other than war (OOTW) on or about December 28, 1998.

[Kenkel, 1999] Kevin Kenkel, Colonel (USAF). "Briefing to Defense Science Board during USAFE Visit", electronic mail, September 6, 1999. 
[Rosenbaum et al., 2000] Mike Rosenbaum, Lt. (USAF), et al. "The Accuracy and Quality of the Air Tasking Orders Executed During the Kosovo Campaign”, briefing, April 14, 2000.

[Switzer, 1998] Warren H. Switzer. "M\&S Tools for the JTF Command and Staff: Enhancing Mission Analysis and Training". Interservice / Industry Training, Simulation and Education Conference, December, 1998.

[Symposium, 1998] Modeling and Simulation Symposium, Hanscom AFB, Massachusetts, November 4-5, 1998.

[WPC, 1998] "Warrior Preparation Center (WPC) NIMBLE LION Initial After-Action Report", briefing, August, 1998.

[Westenhoff, 1990] "Charles M. Westenhoff, Lt Colonel (USAF). Military Air Power: The CADRE Digest of Air Power and Thoughts. Air University Press, Maxwell AFB, Alabama, 1990.

\section{Appendix I: Air Force Task 7 - "Provide Command and Control"'}

AFT 7.1: Monitor Global Conditions and Events

AFT 7.1.1: Receive, Maintain, Integrate, and Display Data From All Sources

AFT 7.1.2: Monitor Status of Global Actions, Critical Events, and Crisis Areas

AFT 7.1.3: Monitor Physical Environment Conditions

AFT 7.1.4: Monitor Status of Friendly Forces

AFT 7.1.5: Monitor Status of Nonfriendly Forces

AFT 7.1.6: Monitor ROE, Treaties and Agreements

AFT 7.2: Assess Global Conditions and Events

AFT 7.2.1: Determine and Assess the Nature and Impact of Critical Events

AFT 7.2.2: Assess Friendly and Nonfriendly Force and Resource Status

AFT 7.2.3: Assess Friendly and NonFriendly Operations and Results

AFT 7.2.4: Determine the Military Implications of Fused Intelligence Indicators,

All-Source Information, and Orders of Battle

AFT 7.2.5: Assess Event Relative to Rules of Engagement, Treaties, and Agreements

AFT 7.2.6: Assess Termination Options, Conditions, and Proposals

AFT 7.3: Plan Military Operations

AFT 7.3.1: Formulate Operations Objectives

AFT 7.3.2: Merge, Generate, and Tailor Force List and Force Movements Requirements

AFT 7.3.3: Develop Potential COAs/Plans

AFT 7.3.4: Evaluate Proposed COAs/Plans

AFT 7.3.5: Select COA/Plan

AFT 7.4: Execute Military Operations

AFT 7.4.1: Execute COA/Plan

AFT 7.4.2: Disseminate Information

\footnotetext{
${ }^{6}$ Air Force Tasks for Command and Control in Air Force Doctrine Document 1-1, 12 August 1998
} 


\section{$\underline{\text { Appendix II: Listing of Potential Decision Support Tools }}{ }^{7}$}

- AATAC (Automated Air Tasking Analysis Capability) - being developed by System Simulation Support Inc (S3I) as a Small Business Innovative Research project for "Time Critical C2" \#AF99-117. Compatible with THUNDER, STORM (THUNDER follow-on), and TBMCS. Designed to generate, analyze, modify, and regenerate ATOs.

- ABAM (Aircraft Beddown Allocation Module) - Force planner matches aircraft requirements to operating location limitations. Produces a solution set of Core Unit Type Code packages and operating locations that can be passed to Joint Logistics Planner. (POC: Synergy, Washington DC).

- ACAAM (Air Courses of Action Assessment Model) - GDE Systems, San Diego, California.

- ACAM (Air Courses of Action Model) - Used in PACOM and by Joint Staff to model Korean scenarios (POC: J8).

- ACPT (Air Combat Planning Tool) - Planning system for CONOPS, centers of gravity, campaign and air component objectives (POC: HQ USAF CHECKMATE).

- AMASS (ATO Modeling and Simulation System) - Used in Blue Flag exercises, Expeditionary Force Experiment (EFX) 98, and Joint EFX 99 to conduct error screening of Air Tasking Orders. Includes a sortie router for threat avoidance. AMASS has grown from smart agent software to include visualization checker. May include simulation using additional parts of the Extended Air Defense Simulation (EADSIM). (POCs: Lt Mike Rosenbaum, 781-377-4633, michael.rosenbaum@hanscom.af.mil; and Mr Carl Opasker, 781271-5782, copaska@ mitre.org).

- ALPS (Area Limitation Planning System) - Sensor planning tool including fixed and UAV platforms (POC: MITRE).

- AMP (Analysis of Mobility Platforms) - Mobilization support tool that generates a TPFDD.

- AWSIM (Air Warfare Simulation) - Air combat model used as part of the Joint Training Confederation; when used with the JQUAD simulation, Warrior Preparation Center has found both useful for Air Tasking Order quality control (POC: AFAMS).

- $\quad$ BCAT (Base Capabilities Assessment Tool) and Unit Type Code Development and Tailoring (UTC DT) - Provide input to COA development and airfield beddown decisions. Links to planning data and factors from existing Joint and USAF systems to develop an analysis of available beddown bases to produce a time-phased assessment for deployment locations. (POC: Synergy, Washington DC, 937-429-8660, 202-232-6261).

- CAPS (Commander's Analysis \& Planning Simulation) - Tool for active defense against ballistic and cruise missiles in theater missile defense (POC: BMDO).

- CASES (Campaign Analysis Simulation and Evaluation System) +POC: BBN Technologies/GTE Interworking, San Diego, California).

\footnotetext{
${ }^{7}$ Sources include [Hartley, 1998], [Switzer, 1998], and [Symposium, 1998]
} 
- CAT (Campaign Assessment Tool) Air Force Research Lab program to develop a graphically based strategy-to-task tool.

- CATS (Consequences Assessment Tool Set) - Natural and technological disaster including war (POC: Defense Special Weapons Agency).

- C2 Decision Process Analysis Toolset (POC: FTI, Washington D.C.)

- CFAM - as a replacement for CTEM in JFACC Planning Tool.

- CBLP (Combat Based Logistics Planner) - beddown assessment tool (POC: Air Force CHEKMATE, AF/XOOC).

- CINC 21 - FY00 ACTD to improve CINC and Joint Force operational commanders' ability to conduct crisis action planning.

- Combined Targeting Board Automation Module - Developed by 7th Air Force.

- COAST (Course of Action Selection Tool) - Comparative analysis of proposed COA based on user-selected criteria applied to military/non-military scenarios.

- CTEM - linear program for force structure studies. (POC: John Hampton, 703-695-8519, postjwh@aol.com).

- Commander's Planning and Execution Tool (CPET) - Joint project of C2 Battle Lab and SPAWAR (see NSS tool description).

- DBC (Dynamic Battle Control) - Capability to more expeditiously discover a relevant military object, determine its importance, declare it a target, and assign weapon to determine the desired effect (used in JEFX 99 and planned for JEFX 2000).

- DCAPES (Deliberate and Crisis Action Planning and Execution System) - Provides commanders and planners a level of information necessary to conduct planning, force tailoring, reporting, and tracking during all phases of operation.

- Decision Support Toolbox (POC: Chi Systems, San Diego).

- DEXES (Deployable Exercise System) - Impact of military force on civilian populations (POC: SOUTHCOM).

- EADSIM (Enhanced Air Defense System) - Analytic model for mission to campaign air defense scenarios (POC: Army Space, Ballistic Missile Defense Organization).

- ELIST (Enhanced Intra-Theater Logistics Support Tool) - Analytic tool for transportation planning (POC: CENTCOM, TRANSCOM).

- FAST-OR (Force Analysis Spreadsheet Tool-OOTW) - Non-combat and support requirements (POC: Army Concepts Analysis Agency).

- FATE (Federated Assessment and Targeting Enhancements) Air Force C2 Battle Lab Initiative to develop a process, CONOPS, and toolset for management of target development (FY00). (POC: Maj Tracy Lunt, DSN 579-8257).

- FDE (Force Deployment Estimator) - Provides first-cut estimates of feasibility of desired deployment of ground, air and sea forces and their sustainment (POC: J8). 
- GDAS (Global Deployment Analysis System) - Theater analysis model for deployment, transportation analysis, CONUS mobilization stations to theater tactical assembly areas, and deployment scheduling (POC: Concepts Analysis Agency).

- HEAT (Headquarters Effectiveness Assessment Tool) - Spreadsheet to assess effectiveness of command and control headquarters (POC: Joint Interoperability Test Command).

- Information Warfare Analysis Model (POC: Innovative Management Concepts, Sterling, Virginia).

- ITE (Integrated Target Environment) USAFE Program teamed with MATTS.

- ITEM (Integrated Theater Engagement Model) - Theater-level model for air and naval planning and analysis (POC: Defense Special Weapons Agency).

- JADE (Joint Assistant for Deployment and Execution) Rapid force deployment planning including a time-phased deployment data (TPFDD) package especially in crisis situations. Air Force Research Lab project with BBN Technologies.

- Janus - Interactive, near real-time model developed to explore relationship between combat and tactical processes using land, sea, and air operations at the battalion or brigade level. Interactive, multi-sided, force-on-force conflict resolution model (POC: National Simulation Center).

- JICM (Joint Integrated Contingency Model) - Interactive theater-level model composed of an integrated family of simulations for ground war (POC: RAND).

- JFACC Decision Support Tool for Time-Critical Targeting -POC: CAD Research Center, Cal Poly Univ).

- JFACC Project - DARPA project to attain agile and stable control of distributed and dynamic military operations conducted in an uncertain and rapidly changing environment. (Air Force POC: Major Cecil Stevens, DSN 579-8237).

- JFAST (Joint Flow and Analysis System for Transportation) - For strategic air and sealift, makes a detailed estimate of transportation requirements and timing (POC: TRANSCOM).

- JICM (Joint Integrated Contingency Model) - Regional or Global conflict simulated for training or analysis (replaced RSAS).

- JIVE (JAOC Information Viewing Environment) - A C2 Battle Lab initiative to develop an integrated information retrieval and display system compatible with near-term JAOC systems. (POC: Maj Stephen M. Matechik, DSN 579-8242).

- JPT (JFACC Planning Tool) First generation strategy-to-task stand-alone planning tool given to each Air operations Center. Being replaced with follow-on Operations Planner. (POC: Air Force CHECKMATE, AF/XOOC).

- JLP (JFACC Planning Tool Logistics Planner) - Evaluate logistic supportability of operational requirements generated by JFACC Planning Tool. Aircraft beddown, munitions availability, supply, maintenance, and transportation evaluated to provide composite assessment of sorties not supported and why. (POC: Synergy, Washington DC, 937-429-8660, 202-232-6261) 
- JTT (Joint Targeting Toolbox) - TBMCS module planned to incorporate strategy-to-task, target prioritization, visualization and prioritization. (POC: AF/XOI).

- KBLPS (Knowledge Based Logistics Planning Shell) - Calculates logistics requirements and allocation and transportation of supplies (POC: CENTCOM, UNC \& CFC Korea).

- LOGCAT (Logistics Contingency Assessment Tools) - Improves the contingency response process. Includes BCAT, UTC-DT, and WRM-CA modules. (POC: Synergy, Washington DC, 937-429-8660, 202-232-6261).

- LPX-MED (External Logistics Processor) - Theater-level logistics COA analysis tool for medical asset networks and evacuation assets in conventional warfare or NBC environments.

- LOGSIM (Logistics Simulator) - Logistics model in the AF Suite of Models for the Joint Training Confederation (POC: USAFE, EUCOM).

- LCOM (Logistics Composite Model) - Relate base-level logistics resources to sortie generation capability. (POC: Fred Juarez, DSN 487-4690, juarezf@ afcqmi.randolph.af.mil).

- MATTS (Mission Analysis Tracking and Tabulation System) - USAFE program to develop a software tool to collect mission reports, and perform real-time and post-strike aircraft and munitions effectiveness assessments.

- MBP (Master Battle Planner) Pre-production ATO visualization system looked at by the Air Force C2 Battlelab as part of the ATO Visualization and Assessment Kenney Battlelab Initiative, August 1997, including looks at ATO/ACO Tool, AMASS, ADEPT/TSCM, ATOX, and ELVIS.

- MAOP (Master Air Operations Planner) Proposed TBMCS module to link strategy-to-task planning to ATO production.

- MIDAS (Model for Intertheater Deployment by Air and Sea) - Intertheater deployment analysis model for movement of combat and support units and sustainment, including all aspects of air and sealift and prepositioning (POC: J4).

- Modeling of C2 Architecture and Performance Estimator -(POC: Schafer Corporation, Chelmsford, Massachusetts).

- Naval Simulation System (NSS) JFACC Planning Tool - Being developed by SPAWAR to read JTL, automatically draft JIPTL, weaponeer JIPTL, generate MAAP through optimization relative to threats, route optimization, fly MAAP for insight into outcomes and predicted BDA and losses.

- OLOGPIN (Operations Logistics Planner) - Estimates materiel needs for all classes of supply (except VII and XI) for Army units down to battalion or company level (POC: UNC \& CFC Korea).

- Operations Planner - Developed by Simulation Support Inc for Air Force CHECKMATE (AF/XOOC). Automates strategy to task development from CINC objectives to MAAP, route optimization using OPUS, and visualization/analysis via EADSIM

- Predictive Modeling and Campaign Simulation (POC: Lockheed Martin, Fort Worth, Texas). 
- $\quad$ RSAS (RAND Strategy Assessment System - Model from 1980s providing theater-level and political-level decision models with branched war plans, giving a tool that could point to need to change plans.

- RESA (Research, Evaluation and Systems Analysis) - Model for Naval warfare used predominantly for training (POC: Naval Research and Development).

- $\quad$ RFPT (Regional Force Projection Tool) - Strategic mobility assessment model for estimating strategic mobility requirements and force closure. (POC: Synergy, Washington DC, 937-429-8660, 202-232-6261).

- SPAM (Sensor Platform Allocation Model) - Used by Air Force Studies and Analysis Agency.

- SPECTRUM - Combines conflict with multi-variate sociological models including political, economic, and socio-cultural effects. (POC: National Simulation Center).

- Strat/TW (Strategy/Theater Warfare Model) - Rapidly examine force structure, explore operational concepts, determine effects of force selections/prioritization. (POC: Synergy, Washington DC, 937-429-8660, 202-232-6261).

- TAM (Theater Analysis Model) - Used to assess quantitative and qualitative issues, assessing COAs and resource planning, addressing conventional combat with provisions for logistics and WMD effects (POC: J8, PACOM, SOUTHCOM).

- TAP (Target Area Planning) - high resolution mission planning, especially for low observable vehicle missions including threat avoidance routing. (POC: Mr David Bonnesar, Bonn Corp, 702-735-5651).

- $\quad$ TERRA (Training for Enemy Rapid Response Allocations) - Civil-military emergency planning (POC: STRICOM).

- SIAM (Situational Influence Assessment Module) - Influence model designed to analyze MOOTW (POC: JFCOM, SAIC).

- Total Airspace Model (TAM) - Developed by CACI to model air sorties from push back at the gate or at chocks to in the gate or chocks at the destination airport.

- STEP (Survey Tool for Employment Planning) - Provide base and airfield information for planning and execution.

- SUMMITS (Scenario Unrestricted Mobility Model for Intra-Theater Simulation) - Model for all phases of inter-theater mobility from port of departure to tactical assembly area and FEBA, with requirements generation from MIDAS and unit movement data from TACWAR (POC: Joint Staff).

- UTC-DT (Unit Type Deployment and Tailoring) - Tailor UTCs in real time. (POC: Synergy, Washington DC, 937-429-8660, 202-232-6261).

- WRM-CA (War Reserve Materiel-Capability Assessment) - Include WRM in tailored UTCs to meet mission requirements. (POC: Synergy, Washington DC, 937-429-8660, 202-2326261). 